\title{
Investigation of Lattice Structures for the Battery Pack Protection
}

\author{
Erol Gültekin ${ }^{1 *}$ and Mehmet Yahşi ${ }^{2}$ \\ 0000-0001-6114-7362 ', 0000-0001-6665-0944² \\ ${ }^{1}$ Mechanical Engineering Department, Faculty of Engineering, University of Turkish Aeronautical Association, Ankara, 06790, Turkey \\ ${ }^{2}$ Mechanical Engineering Department, Faculty of Engineering, Bursa Uludă̆ University, Bursa, 16059, Turkey
}

\begin{abstract}
Transportation market once more put emphasis on electrical and hybrid vehicles to satisfy environmental regulations and disregard fossil fuel price variations. Leading companies in the market and the researchers study on critical units of electrical and hybrid vehicles such as electric motors and batteries which directly affect the vehicle performance on different operating modes. However, battery safety on unusual cases such as crash, explosion or fire caused by the short cut inside the battery pack could damage the other units and the human inside or around the vehicle. On that point, generally, protection of the battery system accomplished by the battery housing with the usage of steel or aluminum sheets. In this study, battery housing designed with sandwich panels constructed with different lattice structures, which could be used in aviation, aerospace, manufacturing industries and biomechanical applications. High strength and stiffness, thermal flow and mass reduction opportunities makes the lattices foremost solution when compared with plain sheet metals. In this scope, the lattice structures were introduced and six different lattice types designed in Solidworks and analyzed in HyperWorks from the point of static loading with $0.2 \mathrm{MPa}$ on upper cover while keeping the lower one fix. Compliance value evaluated for each lattice structure to find linear static response when loaded. Results show that hexagonal honeycomb lattice have superiority on other structures regarding to the compliance value noted as $3.82 \mathrm{Nmm}$ for the load case while $23 \%$ mass increase according to plain sheet metal. For the mass reduction output, cross semicirlcle and 3D kagome lattices presents superiority.
\end{abstract}

Keywords: Battery housing; Electrical vehicles, Hybrid vehicles, Battery pack, Aluminum alloy, Battery safety.

\author{
Research Article \\ https://doi.org/10.30939/ijastech..1020932
}

$\begin{array}{ll}\text { Received } & 08.11 .2021 \\ \text { Revised } & 06.12 .2021 \\ \text { Accepted } & 07.12 .2021\end{array}$

* Corresponding author

Erol Gültekin

egultekin@thk.edu.tr

Address: Mechanical Engineering Department, Faculty of Engineering, University of Turkish Aeronautical Association, Ankara, Turkey

Tel: +903125896108

\section{Introduction}

Automotive manufacturers once more focus on electrical vehicle (EV) and hybrid electrical vehicles (HEV) to meet the environmental demands of strict regulations for the developed/developing countries after more than a hundred years. For this propulsion configuration with respect to internal combustion engine (ICE) vehicles, some problems should be solved related with mainly limited range, charging duration, higher cost per unit weight, etc. In this scope, main constraint seems electric motors and battery technologies and companies mostly gives effort to develop energy density of the batteries to gain superiority over petroleum based ICE [1, 2]. On the other hand, some of the research highlights the battery safety on hazardous cases such as crash, puncturing, flaming, threshold problems on the circuits according to safety regulations. The batteries undergo a series phase tests such as shock, drop, penetration, roll over, immersion, crush, thermal stability and thermal insulation to observe deformation behavior [3-5].

Battery safety accomplished mostly by the aluminum and steel based housing to prevent mechanical deformations against both internal and external cases. On that point, less weight, more robust and higher thermal resistance properties of the covers contributes positive effect to total mass of the vehicle while keeping safety conditions. Many companies research for the better solutions for decades in the field. Hitachi Metals Ltd finds the solution with the usage of $5 \mathrm{~mm}$ thickness of aluminum sheet for battery covers. They used gravity die casting methodology to produce the plates with achieving high stiffness and airtightness [6]. Röchling Automotive Co. offers one shot and one-piece design usage of sheet molding compound materials based on plastics and aluminum. However, that shows greater superiority on aluminum and steel at higher thermal conditions especially with the availability of ceramic coating and protects against the electromagnetic radiation 
and liquid penetration. Up to $40 \%$ weight reduction obtained with respect to steel covers and $30 \%$ for aluminum ones. In their design, tightness gained while preventing the interruption for sealing and removing welding lines due to the manufacturing methods [7]. Tyhssenkrupp Co. uses steel for battery housing and reduces up to $50 \%$ production cost and $\mathrm{CO}_{2}$ emissions due to the production compared to aluminum covers. In the fire protection test, $1.2 \mathrm{~mm}$ thickness of DP-K steel cover presents better performance in safety with accessing $1000{ }^{\circ} \mathrm{C}$ temperature after 20 minutes while Aluminum 6016 access its melting temperature, $610^{\circ} \mathrm{C}$, in 15 seconds [8]. Novalis Co. produces the battery covers with Novelis Advanz ${ }^{\mathrm{TM}}$ aluminum alloy and up to $50 \%$ weight reduction obtained according to steel base covers, which increases range of the vehicle due the lightness [9]. EDAG Engineering offers modular and scalable battery housing with the usage of steel roll form structure base cover, which ensures structural integration for different battery systems [10]. Düser and Schramm studied on a lithium-ion battery housing to simulate the system using temperature of the battery, diurnal ambient temperature, electric waste heat according to heat flow, cooling capacity, and heat flow through the housing. They developed the battery system keeping the temperature under $1000{ }^{\circ} \mathrm{C}$ with respect to ECE R100 standard for the fire protection. A patented semi-permeable membraned pressure relief valve was integrated to prevent the propagation of the highly toxic flue gases to the environment at fire due to the short circuit or damage and crash safety tested with using geometries including meander foam plate, aluminum based hexagonal and round design honeycomb structures and aluminum foam sheets [11].

Xing et al. studied on prismatic type lithium-ion batteries to observe mechanical, electrical and thermal behavior under static and dynamic loading at out of plane and in plane direction depended to the cell surface. For the tests, all cells prepared to $0 \%$ and $50 \%$ state of charge (SOC). The test results shows that oblique cracks occurs on interlayer and some local micro cracks which causes internal short circuit [12]. Vijayaraghavan et al. denoted a holistic solution, genetic programming operating with survival of the fittest principle, to find the maximum force that the battery faced on pinch-torsion test. In the explicit model, increasing the temperature causes decreasing of the force generation while an increase on displacement and strain rate values present an increase on the mechanical force generation. Design input, displacement, dominates the force generation more according to other inputs, temperature and strain rate respectively [13]. Arora and et al. reviewed battery pack layout and design for the robust battery structure of EV. The study presents thermal runaway, protection from the vibration, crash safety, variety in materials and layout of the battery packs, and finally put forward a robust design with the governing standards using Nissan Leaf, Tesla Model S and Chevrolet Volt structure. Battery pack placed on the center of the vehicle structure under the seats reduces the risks especially at frontal and rear collisions. For suitable vibrational isolation, vertical and lateral supports offered [14]. Kalnaus et al. reported mechanical behavior of the pouch cells by out of plane deformation tests both in low and high-speeds loading rates with the usage of 3D X-ray tomography device. They used a 2013 Ford Focus EV battery pack major components, which were subjected to transversal forces in the operation. The experiments shows the pack response stiffening critically that changes the behavior from compressible to crushable type at high-speed deformation rates. Electrode structure was not cracked and due to the compression, only few layer rearranged. A $4 \mathrm{~mm}$ displacement could dissipate the impact on entire battery module, but could cause additional measures for the short circuit safety [15]. Uerlich et al. analyzed rectangular, hexagonal and trapezoidal structures on battery pack design from the point of volumetric efficiency of the packaging, space occupancy rate and crash safety at static and dynamic conditions. According to $10 \mathrm{~mm} / \mathrm{min}$ static loading, energy absorption obtained mostly on hexagonal, rectangular and trapezoidal geometry, respectively. Crash force efficiency nearly same for the three model at low speed rate but at high deformation rate such as $8 \mathrm{~m} / \mathrm{s}$, the geometries shows distinction with getting more efficient rates. The hexagonal structure presented better crash efficiency and followed by trapezoidal and rectangular geometries on both static and dynamic conditions [16].

Above stated researches, battery safety is as important as increasing their energy density chemically. On that point, this study presents an alternative EV/HEV battery housing with the usage of lattice structure on the cover instead of usage of plain sheet metals. Six different aluminum based lattice structures were modelled and analyzed from the point of structural stability on a determined pressure applied to the upper surface and kept the bottom surface fixed. Mass and compliance value were compared with respect to plain sheet metal as a reference.

\section{Battery Structure}

EV/HEV batteries catch on for the last decade but history of this energy storage devices date back to early of 19 th century $[1,17]$. The batteries competed with ICE due to the conversion from chemical energy to electrical energy with higher efficiencies and without gaseous emission operating case. The conversion includes no thermal cycle so that the batteries are not limited by the Carnot cycle efficiency, however, due to the reaction, which could be affected by the other factors such as operating temperature, active material, volume efficiencies etc. could force back from the operation of $100 \%$ efficiency. Generally, the battery cell structure is same for all types, which is categorized according to active material, consist of anode and cathode electrodes that immersed in electrolyte separated with a diaphragm $[18,19]$. With respect to demanded power, the pack composed of many cells and protected by the upper and bottom housing due to the mechanical, electrical, thermal inflow attempt from the external sources. On the other hand, in case of explosion or fire with the short cuts, the housing keeps the exterior systems in safety. For optimal operating temperature, there could be thermal management system on the pack [20, 21]. An exploded view of EV/HEV battery pack and the structure is given in Fig. 1 below. 


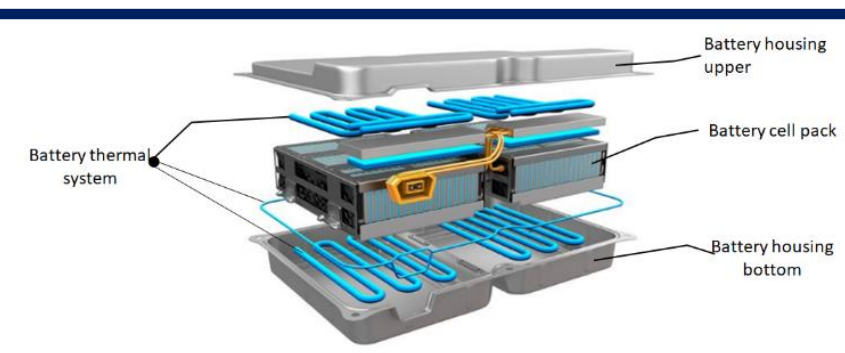

Fig. 1. An exploded view of EV/HEV battery structure [22]

\section{Methodology}

\subsection{Lattice model}

Developing technologies on additive manufacturing such as selective laser melting, ensures complex, unique lattice structures that used widely in aviation, aerospace, defense, and biomechanical industries [23-29].

The lattices could be classified into prismatic, honeycomb and truss based structures. Prismatic lattice materials generally denoted by triangular or diamond corrugations and the Navtruss structures. Honeycomb-like structures are constructed by the webs to shape close contours that are normal to the surfaces. Webs of the honeycomb could be located to set triangular, square or hexagonal cells. On the other hand, truss type lattice structures are connected to random cross section with inclined struts, which could be three, four, or six trusses meeting on a node and shown in the Fig 2 below [30]. Especially, truss based structures have superiority to be fitted to multi-purpose applications thanks to high strength, stiffness and thermo-structural properties with providing interior cooling [31, 32].
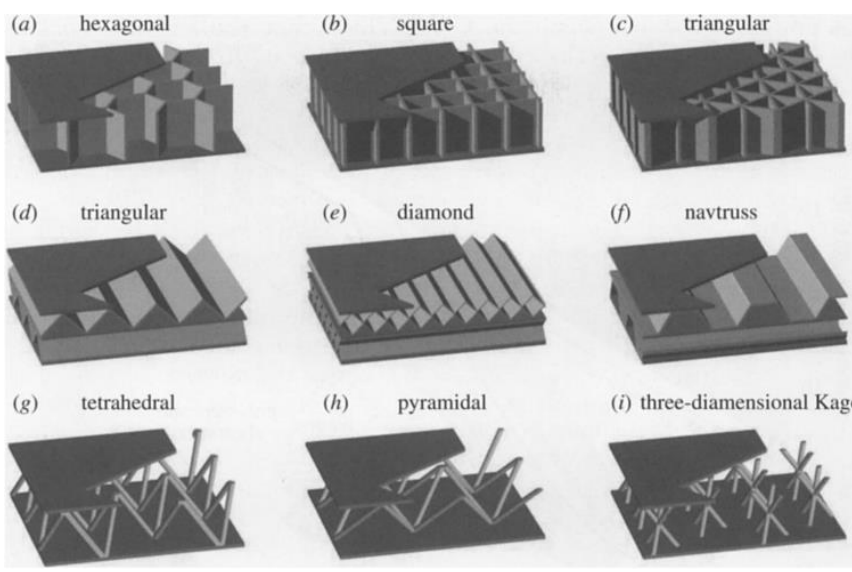

(i) three-diamensional Kagomé

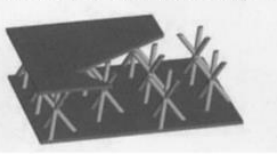

Fig. 2. Lattice structure samples, (a)-(c) are honeycomb, (d)-(f) are prismatic and (g)-(i) are truss type [30]

In this study, identical size lattice structures were designed to obtain light, robust battery housing with pyramidal, cross semicircle, and 3D kagome form. The structural elements were modelled as a sandwich in Solidworks software. For the reference, 100x100x1.5 $\mathrm{mm}$ plain sheet metal was used which is common in the market. Generally, the sheet is stamped for smooth corrugations to increase the reinforcement but to make the analysis on same scenario, plain section was used. Mass of the sheet is 40.5 gram. The plain sheet metal is given in Figure 3.

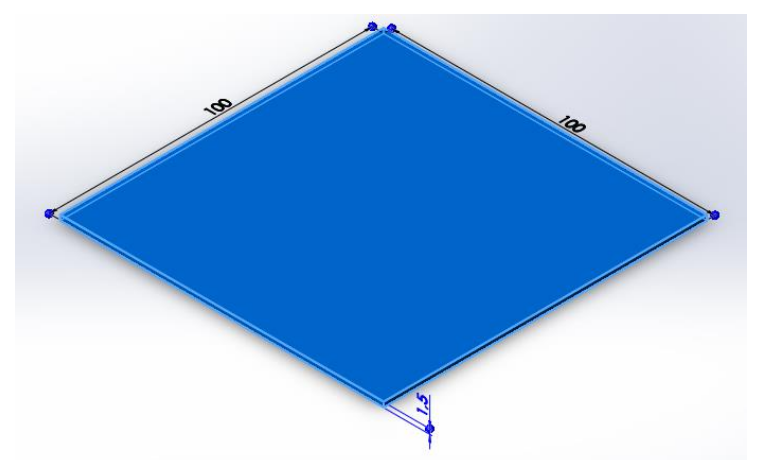

Fig. 3. Plain sheet metal

Pyramidal (Figure 4), cross semicircle (Figure 5), and 3D kagome (Figure 6) lattices were modelled on the same size basement keeping $10 \mathrm{~mm}$ for the each cell. Strut diameter of the truss was taken $1.18 \mathrm{~mm}$. The strut angle was $45^{\circ}$. The structures were also compared with hollow pyramidal (Figure 7), semicircle (Figure 8), and honeycomb (Figure 9) lattices [33]. Wall thickness for the hollow pyramidal strut was $0.095 \mathrm{~mm}$. Upper and lower plate thickness was $0.5 \mathrm{~mm}$ for each type to hold the lattices inside. Total height was obtained $6 \mathrm{~mm}$. Mass of the lattices are given in Table 1 below.

Table 1. Mass of the designed lattices

\begin{tabular}{l|c}
\hline Lattices & Mass [grams] \\
\hline Plain sheet metal & 40.50 \\
\hline Pyramidal & 31.81 \\
\hline Cross semicircle & 36.03 \\
\hline 3D Kagome & 34.20 \\
\hline Hollow pyramidal & 28.41 \\
\hline Semicircle & 31.38 \\
\hline Honeycomb & 49.97 \\
\hline
\end{tabular}

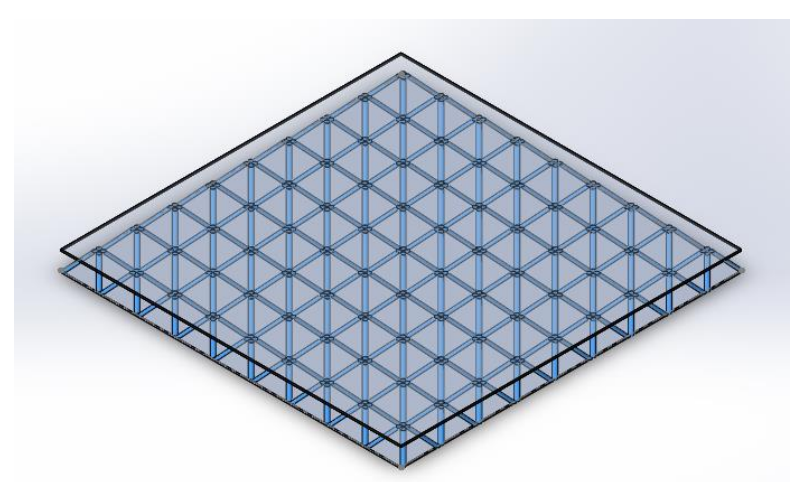

Fig. 4. Pyramidal lattice 


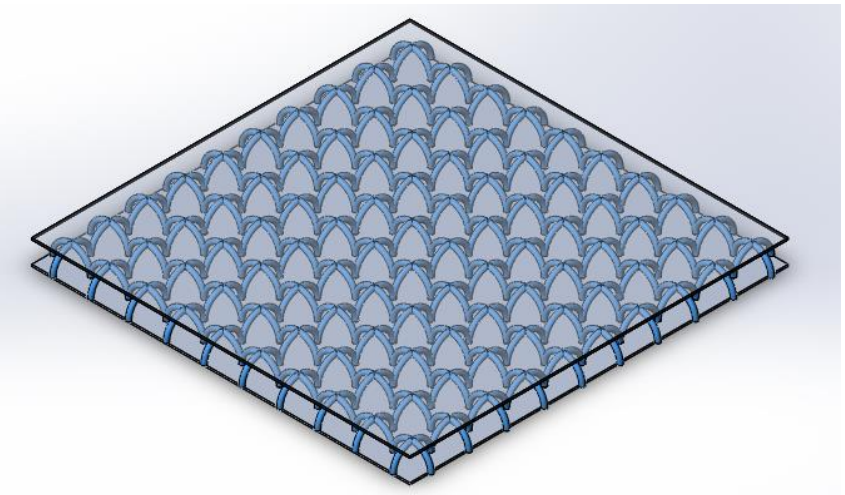

Fig. 5. Cross semicircle lattice

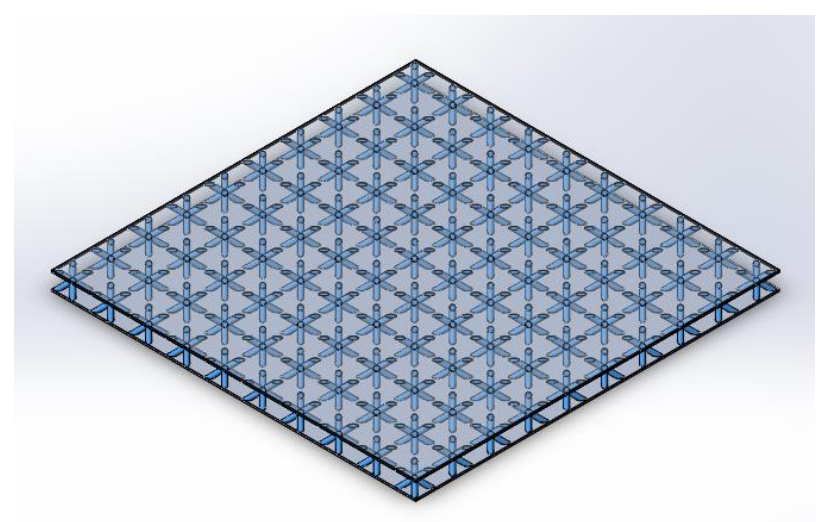

Fig. 6. 3D Kagome lattice

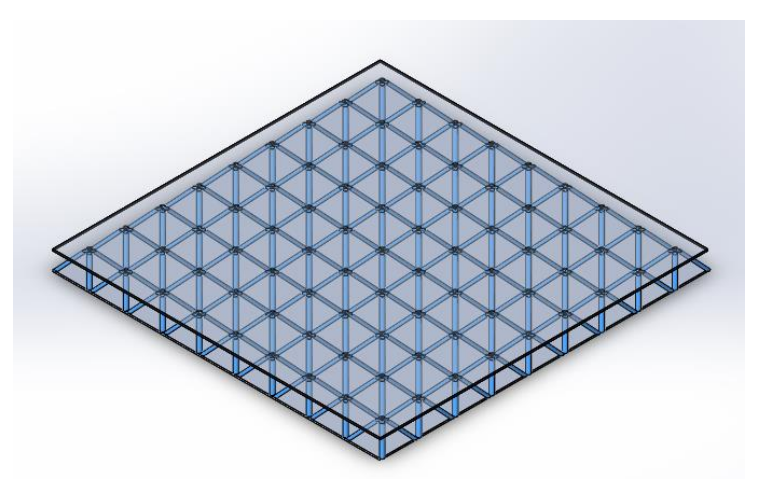

Fig. 7. Hollow pyramidal lattice

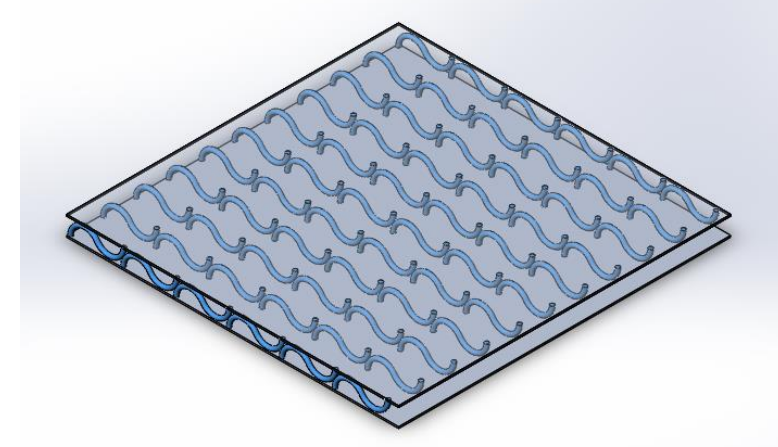

Fig. 8. Semicircle lattice

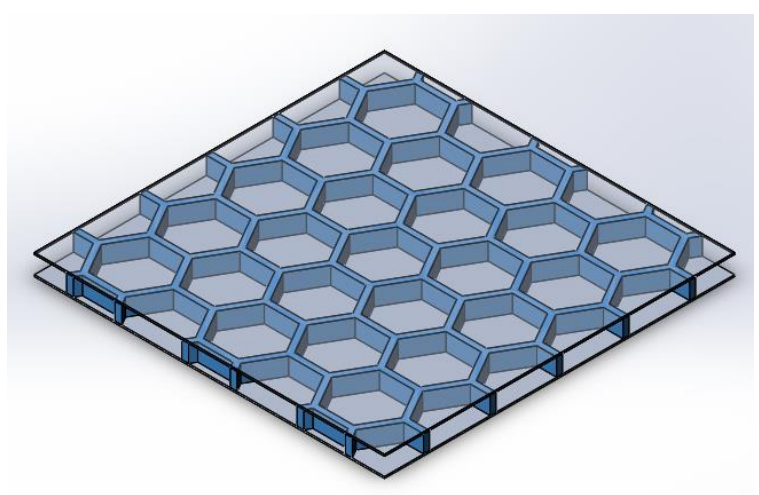

Fig. 9. Hexagonal honeycomb lattice

\subsection{FE model and boundary conditions}

Finite element model of the lattice structures were created to analyze in linear static condition, which shows the stiffness comparison between the lattice models, which are hollow pyramidal, pyramidal, semicircle, cross semicircle, honeycomb and 3D Kagome. FE modeling strategy can be seen in Figure 10.

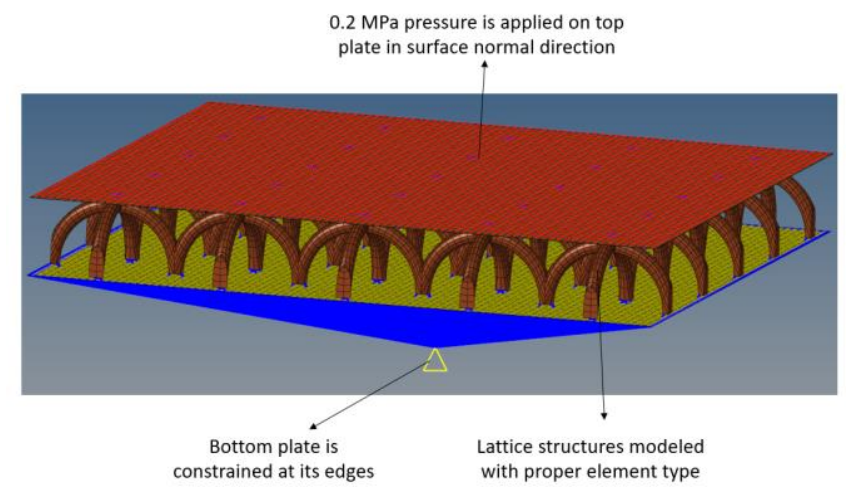

Fig. 10. FE modeling technique for the structures

The lattice structures were located at between two plates. Lower plate was constrained at the edges and 0.2 MPa constant pressure was applied on upper plate. The plates were modelled with quad4 shell elements. Also, empty lattice structures, which had thickness 
were modelled with shell elements, others were modelled with brick and tetras. Lattice structures were fastened to plates with rigid elements. All structures were analyzed with same method. FE model information about the structures is shown in Table 2.

Table 2. FE Model Information

\begin{tabular}{c|c|c}
\hline Structure & Node Number & Element Number \\
\hline Plain sheet & 15625 & 15376 \\
\hline Pyramidal & 66339 & 53365 \\
\hline Cross Semicircle & 37250 & 30146 \\
\hline 3D Kagome & 125518 & 104489 \\
\hline Hollow Pyramidal & 25939 & 24957 \\
\hline Semicircle & 69625 & 59173 \\
\hline Honeycomb & 61626 & 50889 \\
\hline
\end{tabular}

As a material, 6061-T6 aluminum was used regarding its strength and mass advantages. Physical and mechanical properties of the material is given in Table 3.

Table 3. 6061 T6 [33].

\begin{tabular}{c|c}
\hline Density & $2700 \mathrm{~kg} / \mathrm{m}^{3}$ \\
\hline Melting Point & $925 \mathrm{~K}$ \\
\hline Thermal Expansion & $2.4 \times 10^{-5} \mathrm{~K}$ \\
\hline Poisson's Ratio & 0.33 \\
\hline Elastic Modulus & $69 \mathrm{GPa}$ \\
\hline Tensile Strength, Ultimate & $310 \mathrm{MPa}$ \\
\hline Tensile Strength, Yield & $275 \mathrm{MPa}$ \\
\hline Thermal Conductivity & $167 \mathrm{~W} / \mathrm{mK}$ \\
\hline
\end{tabular}

In order to compare structure stiffness under the load conditions, compliance output of the FE analyses was used. This output means, total strain energy of the elements and it can be simply formulated force times deflection. In other words, if the component has high compliance, it has low stiffness.

The compliance, $\mathrm{C}$, is denoted with the Equation 1 below:

$$
C=\frac{1}{2} u^{T} f=\frac{1}{2} \frac{\left(f^{T} f\right)}{K^{T}}=\frac{1}{2} \frac{f^{2}}{K}
$$

For a structure with an applied forces, f subcase, the compliance, $\mathrm{C}$, can be considered a reciprocal measure of the stiffness $\mathrm{K}$, where $\frac{\mathbf{1}}{\mathbf{2}} \boldsymbol{f}^{\mathbf{2}}$ is constant, $\boldsymbol{f}$ is external forces, $\boldsymbol{u}$ is the displacement. For maximum stiffness $\boldsymbol{K}$, the compliance, C, could be reduced. [34].

\section{Results}

At the beginning, plain sheet metal, which has a $1.5 \mathrm{~mm}$ thickness was analyzed according to comparison aim of the study. Later on, pyramidal, cross semicircle, 3D Kagome, hollow pyramidal, semicircle, and honeycomb lattice models' FE analyses was performed. The displacement distributions and the compliance values of compared structures are shown in Figure 11, Figure 12, Figure 13, Figure 14, Figure 15, Figure 16, and Figure 17 , respectively. One quarter of the model was taken to gain time in analysis. The compliance value were $16.45 \mathrm{Nmm}$ for pyramidal, $13.34 \mathrm{Nmm}$ for cross semicircle, and 13.35 $\mathrm{Nmm}$ for 3D kagome. These results evaluated together with the compliance values $20.81 \mathrm{Nmm}$ for the hollow pyramidal, $22.77 \mathrm{Nmm}$ for semicircle,3.82 $\mathrm{Nmm}$ for honeycomb, and 5.31 Nmm for plain sheet metal [33].

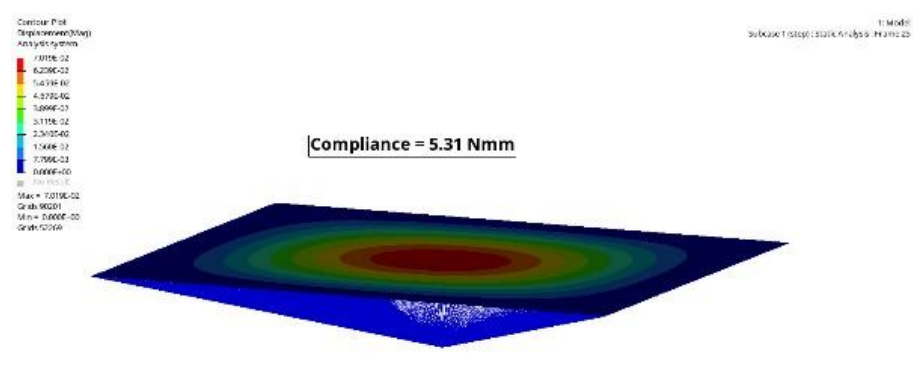

Fig. 11. FE model of plain sheet metal

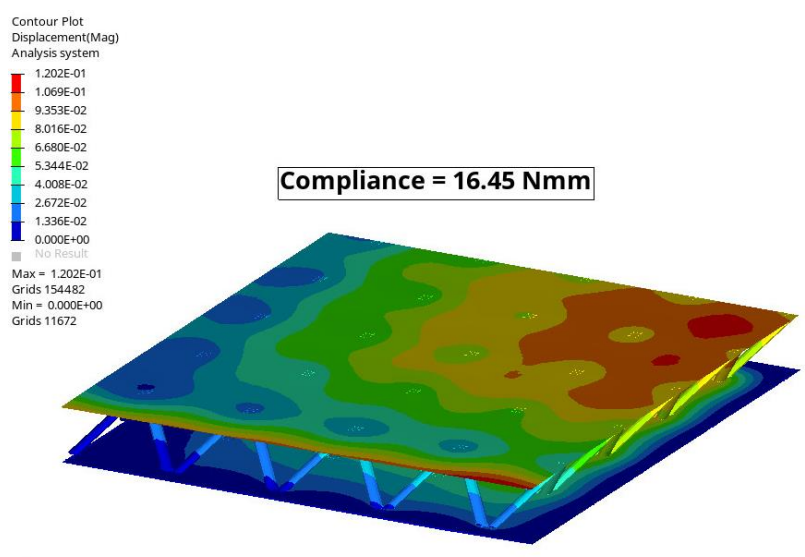

Fig. 12. FE model of pyramidal lattice

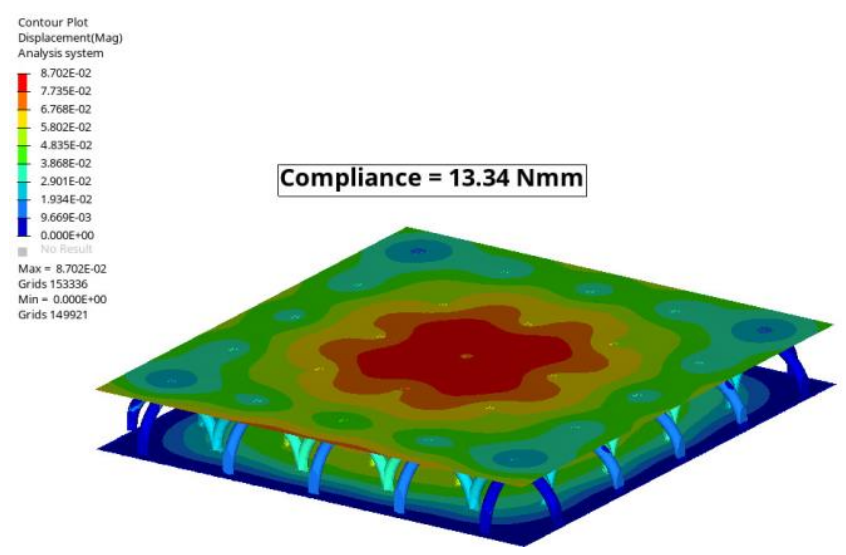

Fig. 13. FE model of cross semicircle 


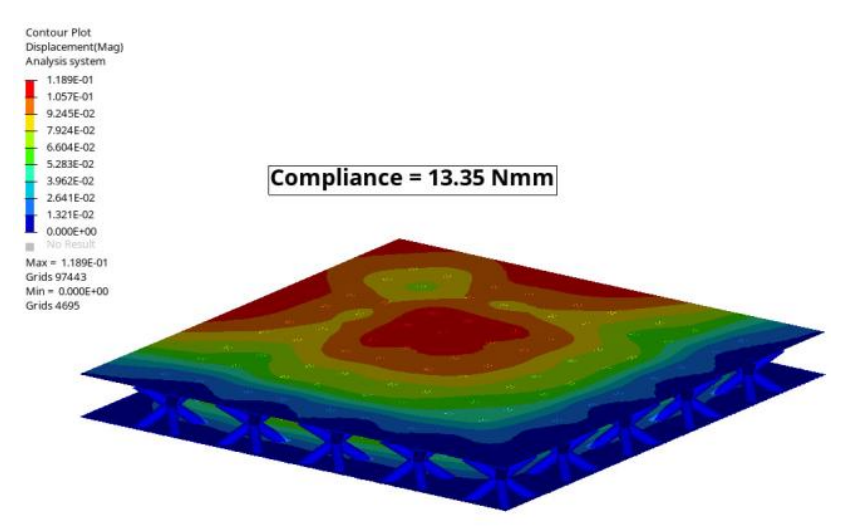

Fig. 14. FE model of 3D kagome lattice

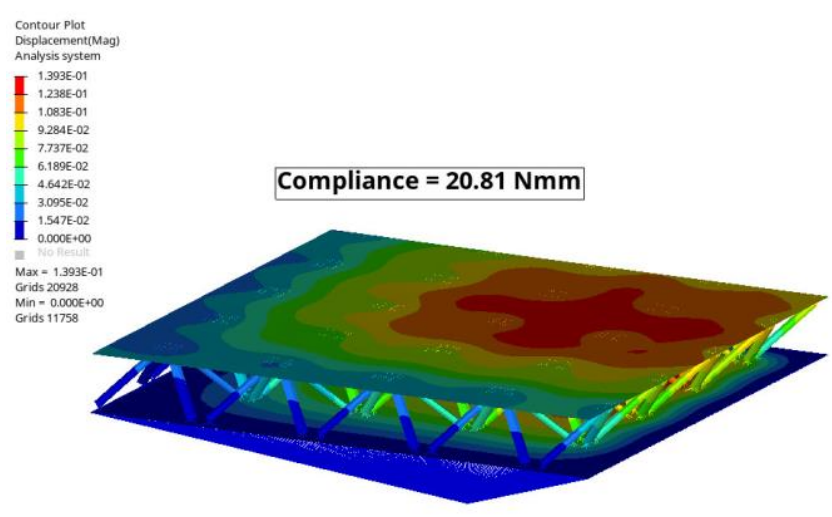

Fig. 15. FE model of hollow pyramidal lattice [33]

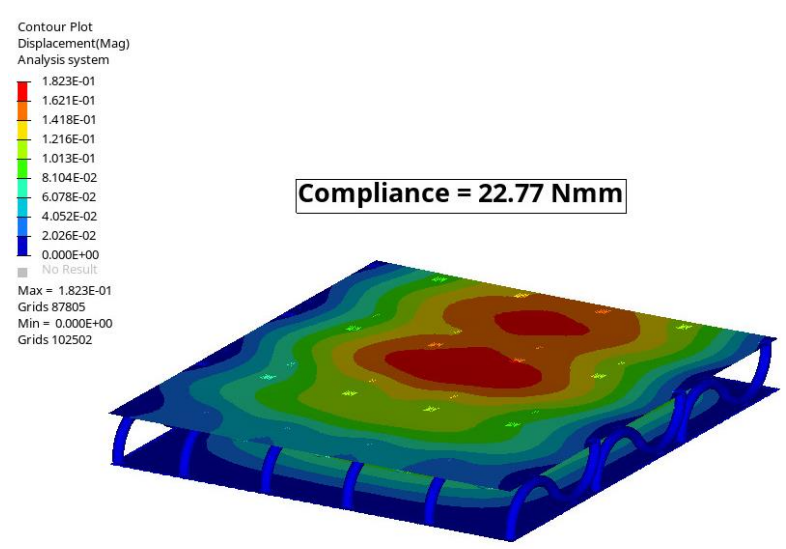

Fig. 16. FE model of semicircle lattice [33]

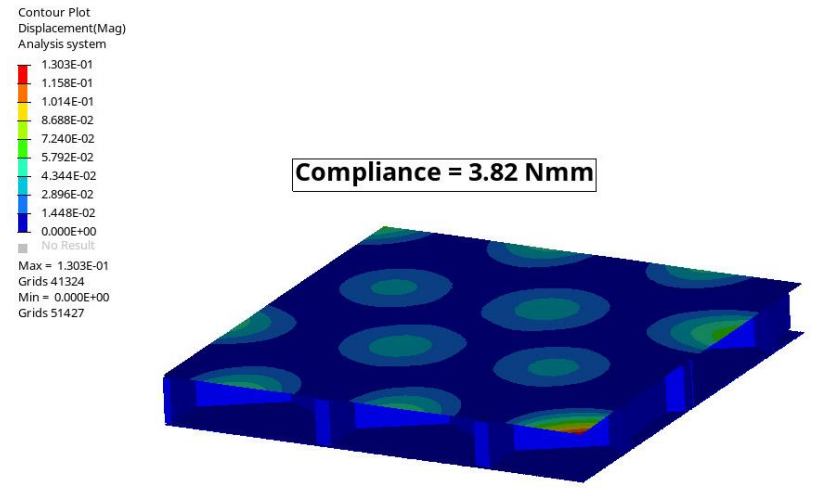

Fig. 17. FE model of honeycomb lattice [33]

The results of the compliance value is given in Table 4 below.

Table 4. Results of compliance, mass change and stiffness comparison with plain sheet metal.

\begin{tabular}{c|c|c|c}
\hline Structure & $\begin{array}{c}\text { Compliance } \\
{[\mathbf{N m m}]}\end{array}$ & $\begin{array}{c}\text { Mass } \\
\text { Change }\end{array}$ & $\begin{array}{c}\text { Stiffness comparison } \\
\text { with Plain Sheet }\end{array}$ \\
\hline Pyramidal & 16.45 & $-21 \%$ & $-210 \%$ \\
\hline Cross Semicircle & 13.34 & $-11 \%$ & $-151 \%$ \\
\hline 3D Kagome & 13.35 & $-16 \%$ & $-151 \%$ \\
\hline Hollow Pyramidal & 20.81 & $-30 \%$ & $-292 \%$ \\
\hline Semicircle & 22.77 & $-23 \%$ & $-329 \%$ \\
\hline Honeycomb & 3.82 & $+23 \%$ & $28 \%$ \\
\hline
\end{tabular}

According to Table 4, due to the load distribution along the strut of the lattices, deformation changes with their stiffness and effects the compliance value. The struts were exposed to shearing forces additionally different from the honeycomb structure, which was only facing compression. So, as an inference, the stiffness is better for the honeycomb structure on the normal loading while the mass is not a factor for the compliance value reduction that could be seen between cross semicircle and $3 \mathrm{D}$ kagome lattices.

\section{Concluding}

In this study, electrical and hybrid vehicle battery pack housing for the protection were investigated and lattice structures introduced to design a light and robust cover. Regarding to lattice structure, pyramidal, cross semicircle and 3D kagome type lattices were designed, and FE models were created to simulate compliance value of each in linear static conditions. Stiffness were compared with hollow pyramidal, semicircle, honeycomb lattices and referenced plain sheet metal. In contrast to proportion of mass reduction increasing, pyramidal, hollow pyramidal and semicircle structures present worse results with respect to plain sheet metal. On the other hand, the honeycomb structure is $28 \%$ stiffer and $23 \%$ heavier than plain sheet. Hollow Pyramidal and Semicircle models are $30 \%$ and $23 \%$ lighter, and they are 
$292 \%$ and $329 \%$ milder, respectively.

This study shows that, instead of using plain sheet metal, the lattice structures could be used to manufacture the housing. When mass reduction as a design output is taken care, cross semicircle and 3D kagome lattices offered. The lattices could be optimized with shape and topology studies to increase the gain on mass and stiffness while keeping the battery pack in safer housing.

$\begin{array}{ll}\text { Nomenclature } \\ \text { EV } & \text { Electrical vehicle } \\ \text { HEV } & \text { Hybrid electrical vehicle } \\ \text { ICE } & \text { Internal combustion engine } \\ \text { SOC } & \text { State of charge } \\ \text { FE } & \text { Finite element } \\ \text { C } & \text { Compliance index } \\ \mathrm{K} & \text { Stiffness index } \\ \text { u } & \text { Displacement in mm } \\ \mathrm{f} & \text { Force in N } \\ T & \text { Total }\end{array}$

\section{Conflict of Interest Statement}

The authors declared no potential conflicts of interest with respect to the research, authorship, and/or publication of this article.

\section{CRediT Author Statement}

Erol Gültekin: Conceptualization, Writing-original draft, Design, Editing,

Mehmet Yahşi: Writing-original draft, Software analysis.

\section{Funding}

The author(s) received no financial support for the research, authorship, and/or publication of this article.

\section{References}

[1] Martins, L. S., Guimaraes, L. F., Junior, A. B. B. and et al. Electric car battery: An overview on global demand, recycling and future approaches towards sustainability. Journal of Environmental Management. 2021: 295, 113091.

[2] Hoeyer, K. G. The history of alternative fuels in transportation: The case of electric and hybrid cars. Utilities Policy. 2008:16(2); 63-71. https://doi.org/10.1016/J.JUP.2007.11.001

[3] Dinçer, İ, Hamut, H. S and Javani, N. Thermal Management of Electric Vehicle Battery Systems, 1st edition, UK, Wiley, 2017.

[4] Bisschop, R, Willstrand, O., Amon, F. and Rosegren, M. Fire Safety of Lithium-Ion Batteries in Road Vehicles. RISE Research Institutes, Boras, Sweden, 2019

[5] Sun, P., Bisschop, R., Niu, H. et al. A Review of Battery Fires in Electric Vehicles. Fire Technol. 2020;56:1361-1410. https://doi.org/10.1007/s10694-019-00944-3

[6] Hitachi Metals Ltd. [internet] https://www.hitachi-metals.co.jp/e/products/auto/ev/battery_case.html (access date: 20.10.2021)

[7] Röhling Automotive Co. [internet] https://www.roechling.com/automotive/products-solutions-1/structural-lightweight/battery-covers (access date: 20.10.2021)

[8] Tyhssenkrupp Co. [internet] https://www.thyssenkrupp$\underline{\text { steel.com/en/industries/automotivetrucks/e-mobility/battery-hous- }}$ ing/ (access date: 20.10.2021)

[9] Novalis Co. [internet] https://www.novelis.com/automotive/electricvehicle-battery-enclosure/ (access date: 20.10 .2021 )

[10]EDAG Engineering Co. [internet] https://insights.edag.com/en/battery-production-a-special-challenge (access date: 21.10 .2021 )

[11]Düser, D., Schramm, T. Battery Housing for Lithium-ion Batteries. ATZ Heavy Duty worldwide. 2019; 12: 36-39, https://doi.org/10.1007/s41321-019-0036-4

[12]Xing, B., Xiao, F., Korogi, Y. and et al. Direction-dependent mechanical-electrical-thermal responses of large-format prismatic $\mathrm{Li}$ ion battery under mechanical abuse. Journal of Energy Storage, 2021; 43: 103270, https://doi.org/10.1016/j.est.2021.103270.

[13]Vijayaraghavan, V., Garg, A. and Gao, L. Fracture mechanics modelling of lithium-ion batteries under pinch torsion test. Measurement 2018;114:382-389, $\quad$ http://dx.doi.org/10.1016/j.measure$\underline{\text { ment.2017.10.008 }}$

[14]Arora, S., Shen, X. and Kapoor, A. Renewable and Sustainable Energy Reviews, 2016; 60:1319-1331, http://dx.doi.org/10.1016/j.rser.2016.03.013

[15]Kalnaus, S.,Wang, H., Watkins, T.R. and et al. Features of mechanical behavior of $\mathrm{EV}$ battery modules under high deformation rate, Extreme Mechanics Letters, 2019: 32: 100550, https://doi.org/10.1016/j.eml.2019.100550.

[16]Uerlich, R., Sanalkumar, K.A., Bokelmann, T., and Vietor, T. Finite element analysis considering packaging efficiency of innovative battery pack designs, International Journal of Crashworthiness. 2020; (25)6: 664-679, DOI: 10.1080/13588265.2019.1632545

[17]Wakefield, E.H. History of the Electric Automobile: Battery-Only Powered Cars. Society of Automotive Engineers Inc., Warrandale, PA, USA, 1994.

[18]Petrovic, S. Battery Technology Crash Course: A Concise Introduction. Springer, Switzerland, 2021.

[19]Wang, S.Fan, Y.Stroe, D.I. and et al. Battery System Modeling. Elsevier, 2021, https://doi.org/10.1016/C2020-0-03232-9

[20]Sun, P., Bisschop, R., Niu, H. et al. A Review of Battery Fires in Electric Vehicles. Fire Technol. 2020;56:1361-1410. https://doi.org/10.1007/s10694-019-00944-3

[21]Pistoia, G. and Liaw, B. Behaviour of Lithium-Ion Batteries in Electric Vehicles: Battery Health, Performance, Safety, and Cost. Springer, Cham, Switzerland, 2018.

[22]Charged Electric Vehicle Magazine [internet] https://chargedevs.com/features/lord-and-scheugenpflug-collaborate-to-scale-up-ev-thermal-designs/ (access date: 03.11.2021)

[23]Maconachie, T., Leary, M., Lozanovski,B., and et. al. SLM lattice structures: Properties, performance, applications and challenges, Ma$\begin{array}{llll}\text { terials } \quad \& \quad \text { Design. } & \text { 2019; }\end{array}$ https://doi.org/10.1016/j.matdes.2019.108137.

[24]Gümrük, R., and Mines, R.A.W. Compressive behaviour of stainless steel micro-lattice structures, International Journal of Mechanical Sciences. 2013; $\quad 68$ : 125-139. https://doi.org/10.1016/j.ijmecsci.2013.01.006 
[25]M. Mazur, M., M. Leary, M., M. McMillan, M., and et al. Mechanical properties of Ti6Al4V and AlSi12Mg lattice structures manufactured by Selective Laser Melting (SLM). Laser Additive Manufacturing: Materials, Design, Technologies, and Applications. Woodhead Publishing Series in Electronic and Optical Materials. 2017; 119-161. https://doi.org/10.1016/B978-0-08-100433-3.00005-1.

[26]Wei, K., He, R., Cheng, X., and et al. Fabrication and heat transfer characteristics of $\mathrm{C} / \mathrm{SiC}$ pyramidal core lattice sandwich panel. Applied Thermal Engineering. 2015; 81: 10-17. https://doi.org/10.1016/j.applthermaleng.2015.02.012.

[27]Alabort, E., Barba, D., and Reed, R.C. Design of metallic bone by additive manufacturing, Scripta Materialia. 2019;164:110-114. https://doi.org/10.1016/j.scriptamat.2019.01.022.

[28]Olmo, E.D., Grande, E., Samartin, C.R. and et al. Lattice structures for aerospace applications. Proceedings of the 12th European Conference on Spacecraft Structures, Materials and Environmental Testing, 2012.

[29]Mark Helou, M and Kara, S. Design, analysis and manufacturing of lattice structures: an overview. International Journal of Computer Integrated Manufacturing. 2017; 31:3, 243-261. https://doi.org/10.1080/0951192X.2017.1407456

[30] Pingle S. M., Fleck N. A., Deshpande V. S. and Wadley H. N. G. Collapse mechanism maps for a hollow pyramidal lattice. Proc. R. Soc. A.467985-1011, 2011. http://doi.org/10.1098/rspa.2010.0329

[31]Tian, J., Lu, T. J., Hodson, H. P., Queheillalt, D. T. and Wadley, H. N. G. Cross flow heat exchange of textile cellular metal core sandwich panels. Int. J. Heat Mass Transfer. 2006; 50, 2521-2536. (doi:10.1016/j.ijheatmasstransfer.2006.11.042)

[32]Wei, K., Yang, Q., Ling, B., Xie, H., and et al. Mechanical responses of titanium 3D kagome lattice structure manufactured by selective laser melting. Extreme Mechanics Letters. 2018; 23: 41-48. https://doi.org/10.1016/j.eml.2018.07.001.

[33]Gultekin, E., Yahsi, M. Analysis of the lattice structures for the battery pack of electrical and hybrid vehicles. Proceedings of 10th International Conference on Engineering \& Natural Sciences, ISPEC Publications 2021. ISBN: 978-625-7720-40-3.

[34]Altair Optistruct 2020 User Guide [internet] https://2020.help.altair.com/2020/hyperworks/pdfs/os/OptiStruct_2020_UserGuide (access date: 07.11.2021) 